\title{
An ICT Integration Approach on Malagasy Agriculture: The Case of Vanilla Production
}

\author{
Ambinintsoa Nantenaina Rakotonanahary, Jianmin Cao \\ College of Economics and Management, Jilin Agricultural University, Changchun, China \\ Email: 2982188390@qq.com
}

How to cite this paper: Rakotonanahary, A. N., \& Cao, J. M. (2020). An ICT Integration Approach on Malagasy Agriculture: The Case of Vanilla Production. Open Journal of Social Sciences, 8, 208-216. https://doi.org/10.4236/jss.2020.86017

Received: January 7, 2020

Accepted: June 9, 2020

Published: June 12, 2020

Copyright $\odot 2020$ by author(s) and Scientific Research Publishing Inc. This work is licensed under the Creative Commons Attribution International License (CC BY 4.0).

http://creativecommons.org/licenses/by/4.0/

(c) (i) Open Access

\begin{abstract}
The cultivation of vanilla is one of the economic pillars of Madagascar. Yet, since its liberalization in 1995, this sector has experienced recurrent production instability. In an attempt to enhance the production performance in this sector, this article will try to study the causes of this production instability, and propose a sustainable alternative to the vanilla production in Madagascar. Indeed, during this research, the empirical research analysis revealed on the one hand a poor communication management of the vanilla sector in the spread of timely information and an annual passage of tropical cyclones. Besides, the literature review suggests that one alternative could be introduced through the integration of new technologies such as ICT.
\end{abstract}

\section{Keywords}

Madagascar Vanilla, Enhance Production, Information Management, ICT Integration

\section{Introduction}

A fundamental innovation of the 21st century was the connection of the world through digital and virtual platforms; ICT was part of this process. The application of ICT was present in many areas such as education, technology, and information, money transfers, scientific, medical and agricultural research, social networks, data collection by the government to its citizens, etc. Over time, ICT has gradually integrated into the field of agriculture commonly known as E-Agriculture. This technology aimed to revolutionize this sector by selecting, sharing, and communicating useful and timely information on the real needs of farmers to improve their production, increase their standard of living and prevent bad weather, various natural disasters, and human threats. Thus, in this study, the integration of ICT in Madagascar vanilla production was an essential 
step to enhance the sector.

\subsection{Madagascar Vanilla Production}

A leader in the vanilla sector, Madagascar consistently produces 65 - 85 percent of total world volume. Indeed, 70\% of Malagasy is farmer and accounts for 24 percent of its gross domestic product (GDP) (Shriver, 2013). In the vanilla sector, there are approximately 80,000 farmers, 6000 collectors, and 33 exporters (Shriver, 2013) on a total area of 25,000 hectares (Andreas, 2006). According to the Observatory of Economic Complexity (OEC), Madagascar remains the dominant country with an average of $51.05 \%$ ( $\$ 250.5$ million) of the market share in 22 years followed by Indonesia with $8.67 \%$ ( $\$ 25.93$ million), Comoros with $3.78 \%$ (\$8.64 million) and Uganda with 2.99\% (\$7.38 million). Although the geographic location offers favorable conditions to vanilla exploitation, it also directly exposes the country to the annual passages of tropical cyclones.

\subsection{Statement of the Problem}

As the Southwest Indian Ocean (SWIO) continues to be the least studied field of study in peer-reviewed literature, it suffers from a limited number of studies related to Tropical cyclones TC (Griffin, 2011). Located in the Indian Ocean, Madagascar is among the most prone and vulnerable countries to meteorological risk in the world. The country is specially opened to cyclones, floods, and seasonal droughts, which frighten agricultural production and livelihoods (SaryTany \& Someah, 2012). According to (Strobl, 2019), the damage generated by tropical cyclones relies principally on three interdependent aspects: wind speed, flooding and/or excess rainfall, and storm surge. Given the recurrent passage of tropical cyclones, this work seeks to determine whether the integration of more modern technology such as the ICT could improve the production of vanilla in Madagascar by the improvement of the prevention and mitigation against tropical cyclones.

\section{Literature Review}

In an economy world, the basis of trade was for each country better off not to isolate itself from all other countries, in other term, a globalization of the economy. The economist Joseph Stiglitz gives the economic globalization a definition as "the closer integration of the countries and the peoples of the world that realized, on one hand, the reduction of the costs of transport and communication, and on the other hand the destruction of artificial barriers to the free movement of goods, services, capital and to a lesser extent persons." The transition from conventional to more advanced practice in developing countries is one of the principal objectives of the 21st century in the agricultural sector. The World Bank reiterated that agriculture remains a dominant sector of the economy since it is around four times more effective at raising incomes among the poor than other sectors. According to the FAO, the growing global population, expected to 
hit 9 billion by 2050, has heightened the demand for food and placed pressure on already-fragile resources. Feeding that population will require a 70 percent increase in food production. Recent research on E-Agriculture, E-sourcebook, and E learning has dedicated an innovation platform in the field of agriculture to improve overall production while being environmentally-conscious for sustainable agricultural and rural development. Two major and cyclical problems were often factors of the Malagasy vanilla crisis, on one hand, the price fluctuations of the products of rent related to the instability of the world markets and on the other hand, the climatic risks due to the exposure of Madagascar's eastern façade to cyclones (Droy, 2017).

\subsection{The Challenges in Malagasy Vanilla Production}

Vanilla is the world's second most expensive spice after saffron; it is an economically important orchid (Tan \& Foan, 2013). The geographical position of Madagascar, specifically on the East Coast of the island provides the perfect conditions for the production of export crops (Droy, Rasolofo, Dubois, Lachaud, Montaud, \& Pouille, 2003). However, during its supply chain process, it is often subject to externalities and market failures such as asymmetric quality information (Olivier, Laure, \& Jaime, 2008). As Madagascar vanilla ordinarily grows within forested zones, obstacles arise in the supply chain process, ranging from mobility such as fertilizer supply, crop distribution to timely communication of essential information such as the passage of tropical cyclone. Furthermore, forest areas are subject to a historical phenomenon of deforestation with agricultural practices still based on slash-and-burn agriculture (Rouvroy, Penot, Le Grusse, Philippe, \& Danthu, 2017). Rice production, particularly on forest areas, could lead to the gradual disappearance of forests and biodiversity which could lead to a decrease or even the destruction of the vanilla sector in Madagascar.

In most low-income countries, particularly in Sub-Saharan Africa (SSA), poverty is above all a rural phenomenon (Olivier, Laure, \& Jaime, 2008). This poverty is often accompanied by the inability or incapacity of farmers to enhance their production. As N. Gregory Mankiw stated "the difference in a standard living reside in countries productivity", according to him, "in nations where workers can produce a large quantity of goods and services per hour, most people enjoy a high standard of living; in nations where workers are less productive, most people endure a more meager existence". Indeed, Malagasy farmers had gradually decreased its vanilla production mainly for the following causes. Firstly, the presence of vanilla theft in the region; Malagasy farmers harvested their vanilla earlier as they are afraid of theft (Lyons, Palamidessi, De Jong, Katzilaki, \& Glass, 2016), in turn; this implies a low quality of the crops that directly impact the price of vanilla. Secondly, the lack of information and technology forces small farmers to resolve information asymmetry and manual cultivation during the production process. N. Gregory Mankiw reiterated that "to boost living standards, policymakers need to raise productivity by ensuring that workers are well educated, have the tools they need to produce goods and services and 
have access to the best available technology".

\subsection{Definition of ICT}

Information and Communication Technology (ICT) is the telecommunication, broadcasting media, and all types of audio and video processing, transmission and network-based control and monitoring functions (Tamilselvan, Sivakumar, \& Dr Sevukan, 2012). It generally refers to the use of new or modern technologies to aid in analysis, storage, processing as well as communication of information. To define ICT, the significance of each term is essential to a better understanding of the concept. Information is generally referring to data that can be recorded, organized, interpreted and that which can be communicated and understood (Tamilselvan, Sivakumar, \& Dr Sevukan, 2012). Communication is the transfer of data among persons, systems, devices (computer, internet, cell phone, television, radio, etc...); whereas, Technology is the making, modification, adaptation and the usage of tools, techniques, systems, and machines to solve problems or completing goals in a less time period. The combination of the two terms Communication Technology covers any product that will store, retrieve, manipulate, transmits or receives information electronically in a digital form (Tamilselvan, Sivakumar, \& Dr Sevukan, 2012).

\subsection{The Use of ICT in Agriculture}

The use of new technology in the field of agriculture is a new concept, nevertheless, it had progressively proved its utility in terms of efficiency, energy-saving and respecting of the environment. The acceleration after the mid-1990s was broad-based-located primarily in ICT-using industries rather than ICT-producing industries (Basu \& Fernald, 2006). According to some researchers, information and reductions in uncertainty improve resource allocations and decision making and reduce delay costs by increasing the accuracy of mental mappings from actions to expected consequences. According to (Aral, Brynjolfsson, \& Alstyne, 2010), access to information should promote information worker productivity by 1) supporting higher quality decisions, 2) facilitating the development of managerial skills and 3) enabling more effective political maneuverability. Their research revealed two main results: first, information flows and IT use predicts greater multitasking and productivity; Second, technology use increases the work speed and open new ways of working that make workers more productive. In our research, the need of information and technology in agriculture and specifically in the vanilla sector in Madagascar were essential for the improvement of the vanilla sector such as the timely and accurate weather prediction, and the use of some basic technological advances as can be seen in Table 1 which might prevent the decrease for the overall annual production.

With the rapid evolution of technologies, the success of ICT in developed countries and its growing expansion in developing countries; many countries, communities could now afford to establish new means of communication and 
Table 1. Overview of new technological advances.

\begin{tabular}{cl}
\hline Technology & \\
\hline $\begin{array}{c}\text { FinTech } \\
\text { industries }\end{array}$ & $\begin{array}{l}\text { They are firms that use new technology and innovation to race in the marketplace. } \\
\text { money transfer, multifactor authentification, payment security solutions for } \\
\text { mobile applications, e-commerce, and financial support. }\end{array}$ \\
It is defined as a great volume of analytic data that uses quantitative and
\end{tabular}

Source: Information and Communications Technology literature review (IAESB), 2018.

have the determination to better educate themselves, develop their cultures and take part in the value chain through communication and global sharing of information since its cost dramatically decreased, mainly due to an increase in competition. In 2017, the FAO reported that in developing countries, farmers face different issues such as the costs to obtain information about consumer (or importers) preferences, the lack of interaction, information, and innovative productive technology due to their isolated communities hinder the supply chain process. FAO proposed two folds conclusion, first, the ICTs had the capability to reduce these costs and enhance production through the use of digital technologies by communication and information sharing, and social connectedness improvement. It allowed small farmers to connect to wider market access and directly meet the consumers and/or importers through e-commerce and provide direct information on prices and price changes. Second, a number of studies provide a range of estimates for the effect of price information on smallholders' sale prices and profits. In 2011, the World Bank also reported that five principal trends have been the principal drivers of the adoption of ICT in agriculture, especially for poor producers: 1) low-cost and pervasive connectivi- 
ty, 2) adaptable and more affordable tools, 3) advances in data storage and exchange, 4) innovative business models and partnerships, and 5) the democratization of information, including the open access movement and social media. Technology sharing in E-Agriculture requires great efforts and trust between countries to compensate for the overall technological inequality. The global storage and share of information in the agricultural sector might be valuable for the improvement of global production. Indeed, the adoption of these new technologies could only work if there are interdependence and equality of technology between the connected countries.

\section{Methodology}

In an attempt to improve the efficiency of vanilla production in Madagascar, this research has opted for a qualitative method which seeks, on the one hand, to reveal the causes of permanent vanilla production instability, and on the other hand, to determine the use of ICT to alleviate this instability. In this context, in-depth research through preliminary studies and documentation on the production of vanilla in Madagascar, and the use of ICT in agriculture was made. The data collections were mainly collected from articles, reports, the FAO, the World Bank, the Observatory of Economic Complexity, and Firinga for meteorological data.

\section{Research Findings}

The stabilization of vanilla production is essential for Madagascar; as a major exporter of vanilla, the instability of supply has a direct impact not only on the international vanilla market but also on the country's economy. Throughout this research, both literature reviews and empirical studies agree on two major issues in Madagascar's vanilla production which are its exposure to annual tropical cyclones, and the lack of management in the delivery of timely information.

\subsection{Tropical Cyclone Risk on Vanilla Production}

A vanilla plant does not produce fruit before its third year; therefore, cyclones present a significant setback for the farmer who loses all of his plants (Packer, 2008). Table 2 below gives us an overview of the annual calendar of different cultures and cyclones that hit the Northeastern part of Madagascar from 2000 to 2019.

The country encountered an outstanding number of 27 cyclones in 20 years; cyclone periods in Madagascar are usually between December and May, however, during these 20 years, they were more concentrated during January $(22.22 \%)$, February (25.92\%), and March (29.69\%). These series of cyclones, over the years, have had a large cumulative impact on the environment and in the farmers' production methods. Indeed, to spare the losses due to cyclones, some producers harvested their crops in an early stage (didn't reached its maturity) which decreased the amount of vanillin present in vanilla and devaluate its quality. 
Table 2. Annual cyclone risks on vanilla culture.

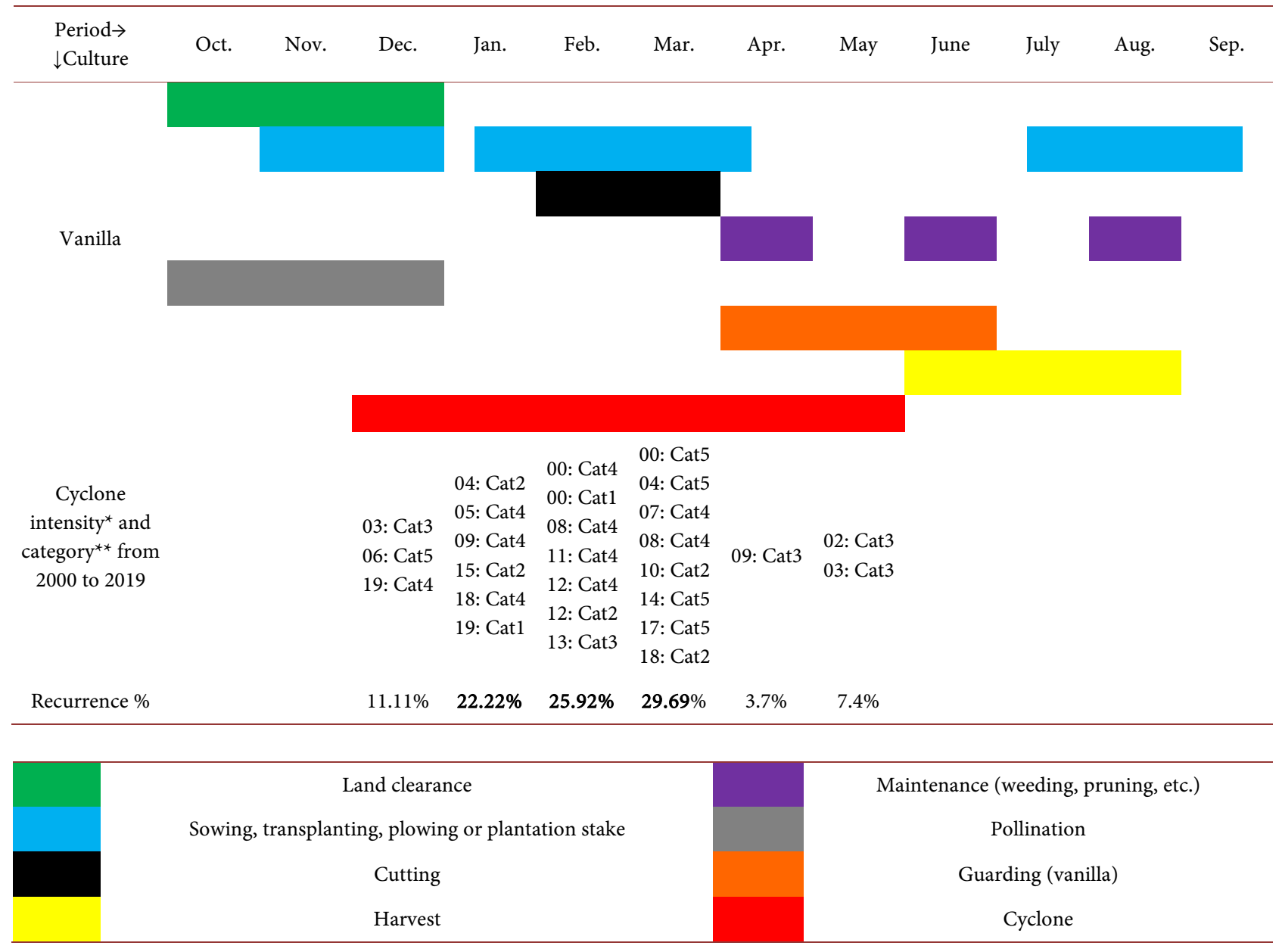

*Intensity: using Dvorak technique which studies the intensity of tropical cyclones on a scale of 0.00 to 8.0 based on the study of satellite photos of visible and infrared spectra. ${ }^{*}$ Category: Cat 1: 2.5 - 3.0 (Moderate Tropical Storm); Cat 2: 3.5 - 4.0 (strong Tropical Storm); Cat 3: 4.5 - 5.0 (tropical cyclone); Cat 4: 5.5 - 6.0 (Intense Tropical Cyclone); Cat 5: 6.5 and higher (intense and very intense tropical cyclone). Source: Author's interpretation.

\subsection{ICT to Enhance Tropical Cyclone Readiness in Madagascar}

With the advancement in technology, such as the Artificial Intelligence and the ICT, their accuracy in providing information adapted to different problems and their spread in the field of agriculture in developing countries make them an alternative for sustainable agricultural and economic growth. In the case of Madagascar, the major part of its vanilla culture is found in the coastal areas, therefore, it is systematically threatened by the seasonal presence of cyclones; the ICT use in this sector could indeed serve as a shield for crop protection by communicating timely information on weather forecasts in remote areas (Figure 1).

Based on several research findings, an ICT initiative implementation in the vanilla sector as prevention and mitigation against natural disasters could be established by the creation of a common information database between the vanilla producing countries on cloud computing. The interpretation of these data could then be extended by an analysis in two forms, on the one hand, by the use of Big Data Analytics for extraction, classification and rapid analysis to reveal hidden 


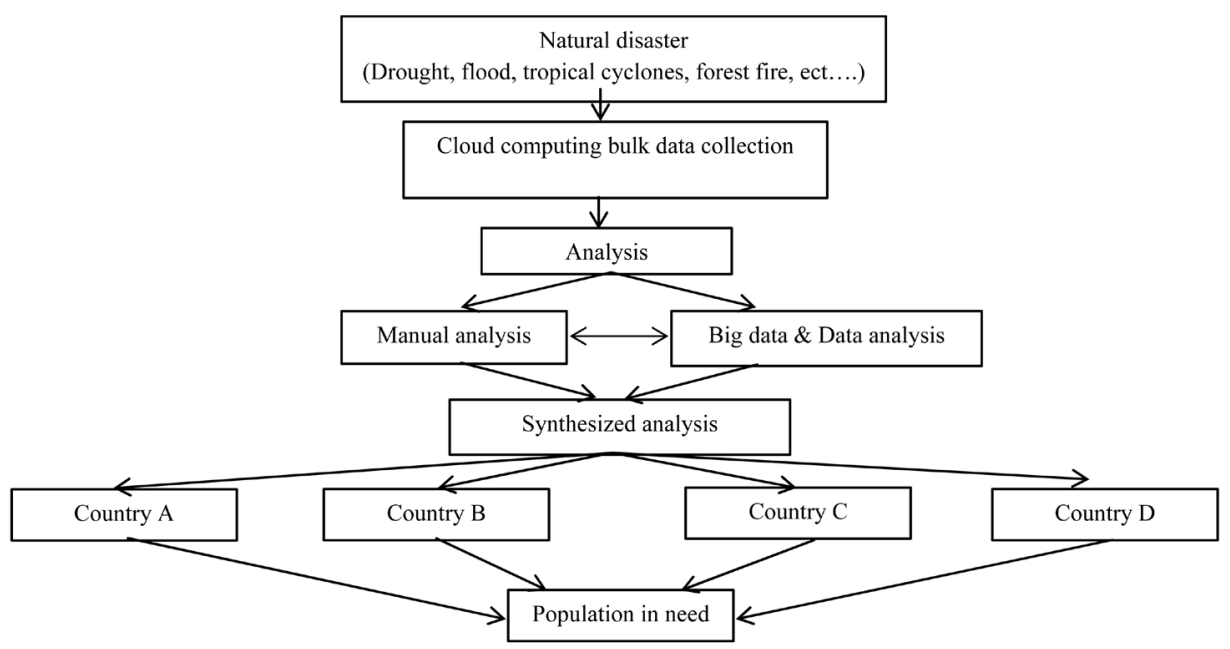

Figure 1. Natural disaster information analysis and spread.

models, undiscovered correlations, etc., and on the other hand, by the manual analysis of the data by researchers and specialists for a pointed and detailed result. This process could be made by an independent or mixed analysis. After the results have been synthesized, the information could be dispersed to the various countries concerned by the use of cloud computing and then be transmitted at a national level to the population by the use of mobile telephony, radio, television, etc... One of the great challenges for researchers during this process is to provide precise, concise information that can be easily assimilated by the group of people in their native language under time pressure.

\section{Conclusion}

The initiative for integrating ICT in agriculture and specifically in the cultivation of vanilla in Madagascar could be an essential lever for the sustainable development of this sector. Numerous researches on its application in developed and developing countries have confirmed its contribution to the growth and socio-economic development, particularly in terms of yield and prevention against natural disasters. Undoubtedly, the integration of this new technology would require a significant investment in the acquisition of infrastructure allowing connectivity and information sharing between producers and experts, however, this investment would contribute to the sustained development of several sectors since its use can be diversified beyond agriculture.

\section{Conflicts of Interest}

The authors declare no conflicts of interest regarding the publication of this paper.

\section{References}

Andreas, C. (2006). Atelier National Vanille: Pour une meilleure compétivité de la vanille de Madagascar. Antananarivo, Madagascar. 
Aral, S., Brynjolfsson, E., \& Alstyne, M. V. (2010). Information, Technology and Information Worker Productivity. Social Science Research Network Paper No. 13172.

Basu, S., \& Fernald, J. G. (2006). Information and Communications Technology as a General-Purpose Technology: Evidence from the U.S Industry Data. https://doi.org/10.2139/ssrn.1004574

Droy, I. (2017). La vulnérabilité des ménages ruraux de la Côte Est de Madagascar.

Droy, I., Rasolofo, P., Dubois, J.-L., Lachaud, J., Montaud, J., \& Pouille, A. (2003). Entre cyclones et marché mondiaux: la vulnérabilité des ménages de la côte est de Madagascar. Bordeaux: Bordeaux (FRA); Pessac: Presses Universitaires de Bordeaux; Université Montesquieu-Bordeaux 4, 2003, 207-222. (Economie Gestion Démographie)

Griffin, K. S. (2011). A Preliminary Climatology of Extratropical Transitions in the Southwest Indian Ocean. New York: Department of Atmospheric and Environmental Sciences, University at Albany, State University of New York.

Lyons, S., Palamidessi, F., De Jong, S., Katzilaki, F., \& Glass, R. (2016). Bittersweet Vanilla: The Unsavoury Story of Vanilla Farmers in Madagascar's Sava Region. Utrecht: CW International, FairFood.

Olivier, C., Laure, D., \& Jaime, D. (2008). The Elimination of Madagascar's Vanilla Marketing Board, 10 Years on. Department of Economics, University of Geneva.

Packer, E. (2008). The Flavor of Money: The vanilla Industry and the Economy of Antalaha. Independent Study Project (ISP) Collection, 571. Los Angeles: University of California.

Rouvroy, C., Penot, E., Le Grusse, Philippe, \& Danthu, P. (2017). Analyse des revenus et modélisation économique et climatique des systèmes agroforestiers, à base de girofliers, dans le district de Mananara (Madagascar). Institut Agronomique Méditerranéen de Montpellier, Université Paul Valéry de Montpellier III: Institut Agronomique Méditerranéen de Montpellier, Université Paul Valéry de Montpellier III.

SaryTany, \& SOMEAH (2012). Atlas de la Vulnérabilité Sectorielle de la région SAVA. SaryTany, SOMEAH.

Shriver, J. (2013). Revitalizing Vanilla in Madagascar: Report on the Feasibility Study to Enhance Small Farmer Participation in the Vanilla Value Chain. Catholic Relief Services.

Strobl, E. (2019). The Impact of Typhoons on Economic Activity in the Philippines: Evidence from Nightlight Intensity. ADB Economics Working Paper Series. https://doi.org/10.22617/WPS190278-2

Tamilselvan, N., Sivakumar, N., \& Dr Sevukan, R. (2012). Information and Communication Technologies (ICT). International Journal of Library and Information Science.

Tan, B. C., \& Foan, C. F. (2013). Vanilla Planifolia: An Economically Important Orchid and Its Propagation. Minerva Biotecnologica, 27, 107-116. 